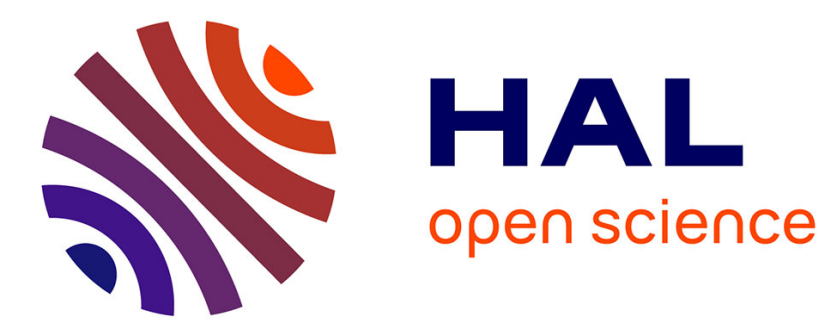

\title{
Evaporation from multi-component canopies: Generalized formulations
}

Jean-Paul Lhomme, Carlo Cesar Montes Verdugo, Frédéric Jacob, Laurent Prevot

\section{- To cite this version:}

Jean-Paul Lhomme, Carlo Cesar Montes Verdugo, Frédéric Jacob, Laurent Prevot. Evaporation from multi-component canopies: Generalized formulations. Journal of Hydrology, 2013, 486, pp.315-320. 10.1016/j.jhydrol.2013.01.038 . hal-02652317

\section{HAL Id: hal-02652317 https://hal.inrae.fr/hal-02652317}

Submitted on 4 Jun 2021

HAL is a multi-disciplinary open access archive for the deposit and dissemination of scientific research documents, whether they are published or not. The documents may come from teaching and research institutions in France or abroad, or from public or private research centers.
L'archive ouverte pluridisciplinaire HAL, est destinée au dépôt et à la diffusion de documents scientifiques de niveau recherche, publiés ou non, émanant des établissements d'enseignement et de recherche français ou étrangers, des laboratoires publics ou privés.

\section{(c)(1)}

Distributed under a Creative Commons Attribution| 4.0 International License 


\title{
Evaporation from multi-component canopies: Generalized formulations
}

\author{
Jean Paul Lhomme*, Carlo Montes, Frédéric Jacob, Laurent Prévot
}

UMR LISAH (INRA, IRD, SupAgro), Laboratoire des Interactions Sol, Agrosystème, Hydrosystème, 2 Place Viala, 34060 Montpellier, France

\begin{abstract}
A general formulation is derived for expressing the evaporation from multi-component canopies representing mixed-plant communities. It generalizes to $n$ components the formulations introduced by Lhomme et al. (Bound-Layer Meteorol. 144, 243-262, 2012) for two and three components models. The new formulation is an alternative and simpler form of the equations previously developed by Wallace (Q. J. R. Meteorol. Soc. 123, 1885-1905, 1997). It is sounder, in the sense that: (i) it accounts for the impact of stomatal characteristics (hypostomatous or amphistomatous) on evaporation expression; (ii) it allows one to eliminate the confusing "Penman-Monteith" type terms of Wallace's formulation (which do no not represent the individual component evaporations). Additionally, the steps of the mathematical demonstration are clearly specified, which was not the case for Wallace's formulation. In this way, a general conceptual framework is defined for evaporation from complex vegetation, from which simpler representations (1,2 or 3 components models) and asymptotic limits (infinite identical components) can be inferred.
\end{abstract}

\section{Introduction}

One of the first model of canopy evaporation is the "big-leaf" model of Penman-Monteith (Monteith, 1965), which describes the evaporation from homogeneous and dense canopies. Since then, more complex models were developed for representing the evaporation from non-homogeneous vegetation canopies, beginning with sparse vegetation, where soil and plant components carry equal status (Shuttleworth and Wallace, 1985; Choudhury and Monteith, 1988; Shuttleworth and Gurney, 1990). Later, these two-source models were extended to heterogeneous canopies with more than two components (Dolman, 1993; Brenner and Incoll, 1997; Wallace, 1997; Verhoef and Allen, 2000): the evaporation from the whole canopy is quantified, as well as that from each component, accounting for the interactions between them. Recently, Lhomme et al. (2012) re-examined some aspects of these multi-source representations, showing that the stomatal characteristics of the foliage (amphistomatous or hypostomatous) generate different formulations for component resistances (stomatal and boundary-layer) and consequently for the evaporation from the whole canopy. They derived new generic equations for two and three-source models, which are valid in both stomatal configurations and are more concise than those traditionally based upon the "Shuttleworth-Wallace" formalism. Given that these new formulations have the same basic structure for one, two or three components, a remaining question was to know whether they can be extrapolated to multi-component canopies (i.e., $n$ sources).

\footnotetext{
* Corresponding author. Tel.: +33 4996131 30; fax: +33 467632614 . E-mail address: jean-paul.lhomme@ird.fr (J.P. Lhomme).
}

Wallace (1997) addressed the issue of modelling evaporation from multi-species canopies by generalizing to $n$ components the formulations originally given by Shuttleworth and Wallace (1985) for two components. Wallace's formulations for evaporation are part of the ERIN model, which also includes a radiation interception sub-model. However, several weaknesses can be identified in the evaporation sub-model of ERIN, as presented in the original article and also in a subsequent one (Wallace and Verhoef, 2000). First, the general formulation for the evaporation from $n$ components (Wallace, 1997, Eqs. (34)-(37)) is not mathematically demonstrated: only the final formula (which is not obvious) is given. Second, the formulation does not account for the differences generated by the stomatal characteristics of each component (amphistomatous versus hypostomatous), as pointed out by Lhomme et al. (2012) for two and three components. Third and most important, it retains a rather complex "Shuttleworth-Wallace" formalism involving $n$ "Penman-Monteith" type terms, which can be confusing given that each term does not represent the respective component evaporation.

In parallel with this approach, Verhoef and Allen (2000) developed a four-component model that accounts for canopy stomatal characteristics and was applied to a dry-land savannah consisting of shrubs, forbs, grasses and bare soil. Although it is based upon the same Shuttleworth-Wallace formalism as the ERIN approach, this model is somewhat different in so far as the fractional coverage of each component is introduced into the formulation, as in Dolman (1993) and Huntingford et al. (1995), following a kind of "patch" approach (Lhomme and Chehbouni, 1999). All four components receive the full radiation load and each Penman-Monteithlike term is multiplied by the corresponding fractional cover. It is 


\section{Nomenclature}

A available energy of the whole canopy $\left(\mathrm{W} \mathrm{m}^{-2}\right)$

$A_{i} \quad$ available energy of component $i\left(\mathrm{~W} \mathrm{~m}^{-2}\right)$

$R_{n} \quad$ net radiation of the whole canopy $\left(\mathrm{W} \mathrm{m}^{-2}\right)$

$G \quad$ soil heat flux $\left(\mathrm{W} \mathrm{m}^{-2}\right)$

$H^{n} \quad$ sensible heat flux from the whole canopy $\left(\mathrm{W} \mathrm{m}^{-2}\right)$

$H_{i} \quad$ sensible heat flux from component $i\left(\mathrm{~W} \mathrm{~m}^{-2}\right)$

$\lambda E^{n} \quad$ latent heat flux from the whole canopy $\left(\mathrm{W} \mathrm{m}^{-2}\right)$

$\lambda E_{i} \quad$ latent heat flux from component $i\left(\mathrm{~W} \mathrm{~m}^{-2}\right)$

$D_{a} \quad$ vapour pressure deficit at reference height (Pa)

$D_{m} \quad$ vapour pressure deficit at canopy source height (Pa)

$e_{a} \quad$ vapour pressure at reference height (Pa)

$e_{m} \quad$ vapour pressure at canopy source height (Pa)

$e^{*}(T) \quad$ saturated vapour pressure at temperature $T(\mathrm{~Pa})$

$T_{a} \quad$ air temperature at reference height $\left({ }^{\circ} \mathrm{C}\right)$

$T_{m} \quad$ air temperature at canopy source height $\left({ }^{\circ} \mathrm{C}\right)$

$T_{c, i} \quad$ surface temperature of component $i\left({ }^{\circ} \mathrm{C}\right)$

$u_{*} \quad$ friction velocity $\left(\mathrm{m} \mathrm{s}^{-1}\right)$

$u_{m} \quad$ wind speed at canopy source height $\left(\mathrm{m} \mathrm{s}^{-1}\right)$

$c_{p} \quad$ specific heat of air at constant pressure $\left(\mathrm{J} \mathrm{kg}^{-1} \mathrm{~K}^{-1}\right)$

$\rho \quad$ air density $\left(\mathrm{kg} \mathrm{m}^{-3}\right)$

$\gamma \quad$ psychrometric constant $\left(\mathrm{Pa} \mathrm{K}^{-1}\right)$

$\Delta \quad$ slope of the saturated vapour pressure curve $\left(\mathrm{Pa} \mathrm{K}^{-1}\right)$

\section{Canopy structural characteristics}

$d \quad$ canopy displacement height $(\mathrm{m})$

$L A I_{i} \quad$ leaf area index of component $i\left(\mathrm{~m}^{2} \mathrm{~m}^{-2}\right)$

worthwhile stressing that this formulation is even more confusing than the ERIN one: given that each "Penman-Monteith" term does not represent the corresponding component evaporation, their multiplication by the corresponding fractional cover has no real physical meaning and can be truly misleading.

Setting the appropriate formalism is essential such that model parameters can be properly estimated when conducting calibration processes. In this context, the present study aims at developing generic equations for the evaporation from canopies with $n$ components (or species), following the same lines as the ERIN model, but with the simpler and sounder mathematical formalism introduced by Lhomme et al. (2012) for two and three-components canopies. In this way, the main shortcomings of the previous multi-component evaporation models will be eliminated.

\section{Basic expressions for component fluxes}

The general case, where the canopy is composed of $n$ components (soil surface included), is illustrated in Fig. 1. Each evaporation component $\left(\lambda E_{i}\right)$ is calculated separately from equations of the Penman-Monteith type involving the corresponding available energy $\left(A_{i}\right)$ and the vapour pressure deficit $D_{m}$ at the mean canopy source height $z_{m}$ (assumed to be located at the apparent sink for momentum: $d+z_{0}$ ). The available energy of each component can be determined from a radiation interception model, such as the one described in the ERIN model (Wallace, 1997). Similarly to the ERIN model, the total evaporation from the canopy is logically written as the simple sum of the individual contributions

$\lambda E^{n}=\sum_{i=1}^{n} \lambda E_{i}$.

Given that fluxes are expressed per unit area of land surface, the corresponding resistances should be expressed in the same way. So, the leaf stomatal resistance $r_{s, l, i}$ (one side) of component $i$ and
LAI leaf area index of the whole canopy $\left(\mathrm{m}^{2} \mathrm{~m}^{-2}\right)$

$n \quad$ number of components (soil surface included)

$z_{r} \quad$ reference height $(\mathrm{m})$

$z_{h} \quad$ mean canopy height $(\mathrm{m})$

$z_{m} \quad$ mean canopy source height $\left(=d+z_{0}\right)(\mathrm{m})$

$z_{0} \quad$ canopy roughness length (m)

$v_{i} \quad$ parameter with value of 1 for amphistomatous and 2 for hypostomatous foliage

\section{Component resistances}

$r_{a, 0} \quad$ aerodynamic resistance between the source height and the reference height $\left(\mathrm{s} \mathrm{m}^{-1}\right)$

$r_{a, i}^{\prime} \quad$ aerodynamic resistance for the vertical transfer within layer $i\left(\mathrm{~s} \mathrm{~m}^{-1}\right)$

$r_{a, i} \quad$ bulk boundary-layer resistance of component $i$ for sensible heat $\left(\mathrm{s} \mathrm{m}^{-1}\right)$

$r_{a, v, i} \quad$ bulk boundary-layer resistance of component $i$ for water vapour $\left(\mathrm{s} \mathrm{m}^{-1}\right)$

$r_{s, i} \quad$ bulk stomatal resistance of component $i\left(\mathrm{~s} \mathrm{~m}^{-1}\right)$

$r_{s, n} \quad$ soil surface resistance to evaporation $\left(\mathrm{s} \mathrm{m}^{-1}\right)$

$r_{s, l, i} \quad$ leaf stomatal resistance (one side) of component $i$ $\left(\mathrm{s} \mathrm{m}^{-1}\right)$

$r_{a, l, i} \quad$ leaf boundary-layer resistance (one side) of component $i$ for sensible heat and water vapour $\left(\mathrm{s} \mathrm{m}^{-1}\right)$ the corresponding leaf boundary-layer resistance for latent heat $r_{a, l, i}$ (one side) should be divided by the transpiring surface expressed per unit area of land surface: $2 L A I_{i}$ for amphistomatous leaves and $L A I_{i}$ for hypostomatous leaves $\left(L A I_{i}\right.$ being the leaf area index of component $i$ ). For convenience, we introduce the parameter $v_{i}\left(v_{i}=1\right.$ for amphistomatous leaves and $v_{i}=2$ for hypostomatous leaves), that allows the bulk stomatal and boundary-layer resistances of component $i$ to be written in a unique form as:

$r_{s, i}=v_{i} r_{s, l, i} /\left(2 L A I_{i}\right)$,

$r_{a, v, i}=v_{i} r_{a, l, i} /\left(2 L A I_{i}\right)$.

The bulk boundary-layer resistance for sensible heat remains the same in both cases (amphistomatous or hypostomatous), since each leaf side is a heat source. It is defined for component $i$ as:

$r_{a, i}=r_{a, l, i} /\left(2 L A I_{i}\right)=r_{a, v, i} / v_{i}$

The hyperstomatous case (stomata only on the upper side of the leaves) is similar to the hypostomatous case and the corresponding expressions of bulk resistances are identical. Jones (1992) gives the dependence of leaf boundary-layer resistance on wind speed $(u)$ at the same level: $r_{a, l}=\alpha(w / u)^{1 / 2}$, where $w$ is leaf width and $\alpha$ a constant coefficient depending on leaf characteristics. It has been shown (Appendix A in Lhomme et al., 2012) that the elementary flux emanating from component $i$ and contributing to the total flux of evaporation can be written in the general form:

$\lambda E_{i}=\frac{\Delta A_{i}+\rho c_{p} D_{m} / r_{a, i}}{\Delta+\gamma\left(v_{i}+r_{s, i} / r_{a, i}\right)}$

with $D_{m}=e^{*}\left(T_{m}\right)-e_{m}$. For the substrate or soil surface, assumed to represent the $n$th component of the system, the same equation holds, with $v_{n}=1 ; r_{s, n}$ representing the surface resistance to evaporation and $r_{a, n}$ the sum of the boundary-layer resistance and the aerodynamic resistance between the substrate and the source 


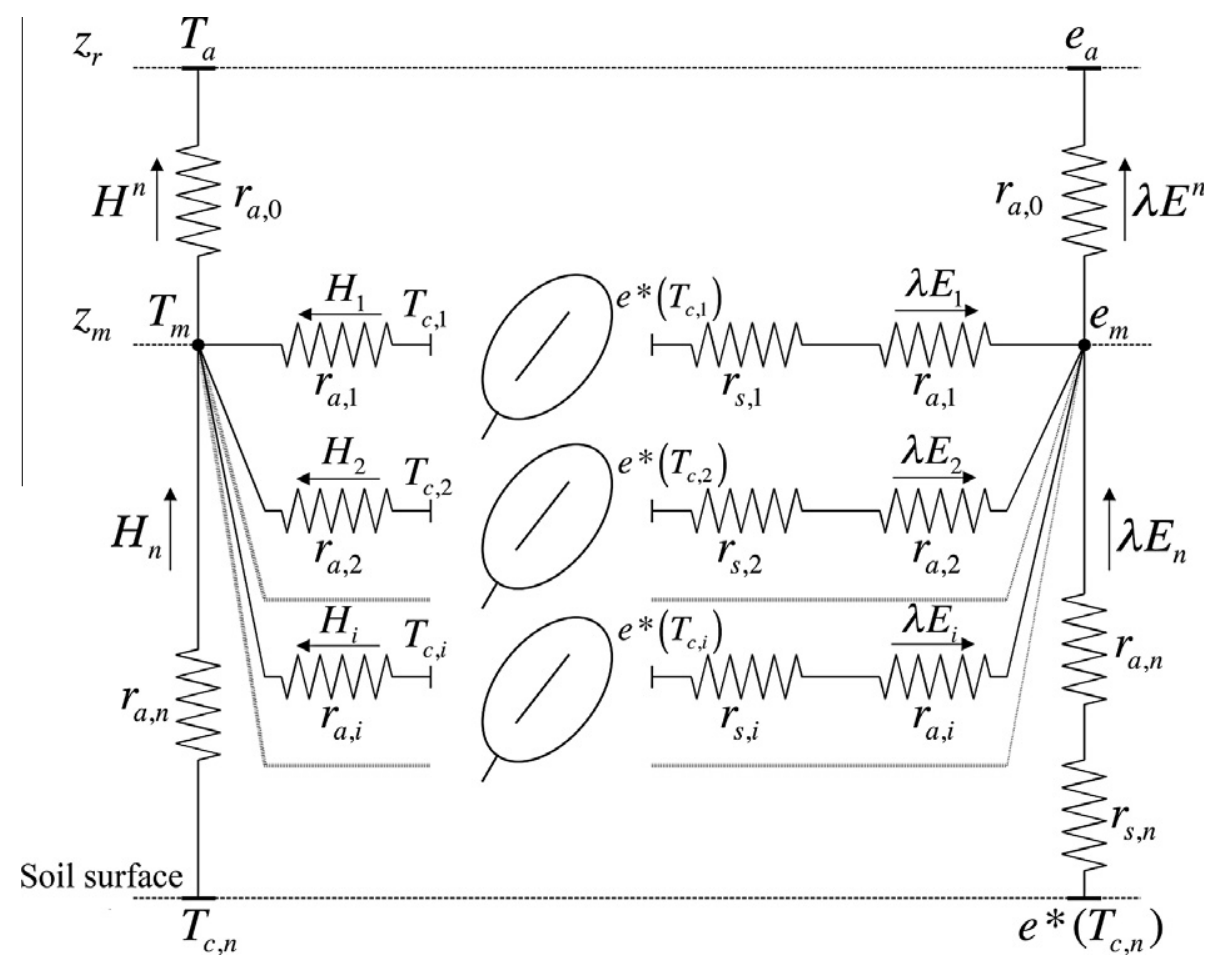

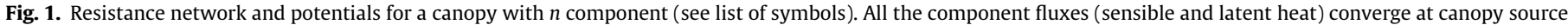
height $\mathrm{z}_{\mathrm{m}}$.

height $\left(z_{m}\right)$, the latter being defined by integrating the reciprocal of the appropriate eddy diffusivity (Choudhury and Monteith, 1988, Eq. (22)).

It is worthwhile stressing that this multi-component approach is different from the multi-layer approach (as represented in Fig. 2), where an homogeneous and high canopy is divided into many parallel layers exchanging heat and water vapour with the air at each level of the stand (Waggoner and Reifsnyder, 1968; Lhomme, 1988). In the latter approach, an additional aerodynamic resistance $\left(r_{a, i}^{\prime}\right)$, linked to turbulent diffusivity, is included within each layer in relation to the vertical transfer of sensible heat and water vapour within the canopy. Air saturation deficit, as wind velocity, is also different within each vegetation layer, contrary to the multi-component approach, where each vegetation component is subject to the same air vapour pressure deficit $\left(D_{m}\right)$ and the same wind velocity $\left(u_{m}\right)$ at canopy source height. In this respect, we have to note that in the "second" version of the ERIN model (Wallace and Verhoef, 2000) an extra resistance called "withincanopy aerodynamic resistance" and calculated from eddy diffusivity (as for the soil surface) is added to the leaf boundary-layer resistance for representing the transfer within the canopy. From a theoretical standpoint, this addition is not perfectly sound, because it contradicts the fact that each component is subject to the same air vapour pressure deficit at canopy source height. The stratification of the exchange levels (implied by this addition) implies de facto a multi-layer approach and not a multi-component one.

\section{Generalized formulae for the evaporation from $n$ components}

The vapour pressure deficit $\left(D_{m}\right)$ in Eq. (5) is calculated from the vapour pressure deficit at reference height $D_{a}\left[=e^{*}\left(T_{a}\right)-e_{a}\right]$ following Shuttleworth and Wallace (1985, Eq. (8))

$D_{m}=D_{a}+\left[\Delta A-(\Delta+\gamma) \lambda E^{n}\right] r_{a, 0} /\left(\rho c_{p}\right)$, where $A\left(=R_{n}-G\right)$ is the available energy of the whole canopy, $\lambda E^{n}$ the flux of evaporation from the whole canopy ( $n$ components) and $r_{a, 0}$ the aerodynamic resistance between the mean source height and the reference height. To simplify the formulations we put:

$R_{0}=\left(1+\frac{\Delta}{\gamma}\right) r_{a, 0}$,

$R_{i}=r_{s, i}+\left(v_{i}+\frac{\Delta}{\gamma}\right) r_{a, i}$

Introducing Eq. (6) into Eq. (5) and after some rearrangements we obtain:

$\lambda E_{i}=\frac{R_{0}}{R_{i}}\left[\frac{\Delta A+\rho c_{p} D_{a} / r_{a, 0}}{\Delta+\gamma}+\left(\frac{\Delta}{\gamma}\right) \frac{A_{i} r_{a, i}}{R_{0}}-\lambda E^{n}\right]$.

The first term of the square bracket is the Penman equation representing the potential evaporation of the canopy (defined by assuming saturation at canopy source height $D_{m}=0$ ). Putting:

$\lambda E_{p}=\frac{\Delta A+\rho c_{p} D_{a} / r_{a, 0}}{\Delta+\gamma}$,

the resulting formula can be rewritten as:

$\lambda E_{i}=\left[R_{0}\left(\lambda E_{p}-\lambda E^{n}\right)+(\Delta / \gamma) r_{a, i} A_{i}\right] / R_{i}$.

Eq. (11) shows that the evaporation from an individual component depends on the evaporation from the entire canopy, confirming the interaction between the different components. Substituting Eq. (11) into Eq. (1) and collecting the terms in $\lambda E^{n}$ gives:

$\lambda E^{n}=R_{0}\left(\sum_{i=1}^{n} P_{i}\right) \lambda E_{p}+\left(\frac{\Delta}{\gamma}\right) \sum_{i=1}^{n} P_{i} A_{i} r_{a, i}$,

with the coefficients $P_{i}$ defined as:

$P_{i}=\frac{1}{R_{i}\left[1+R_{0} \sum_{j=1}^{n}\left(\frac{1}{R_{j}}\right)\right]}$. 


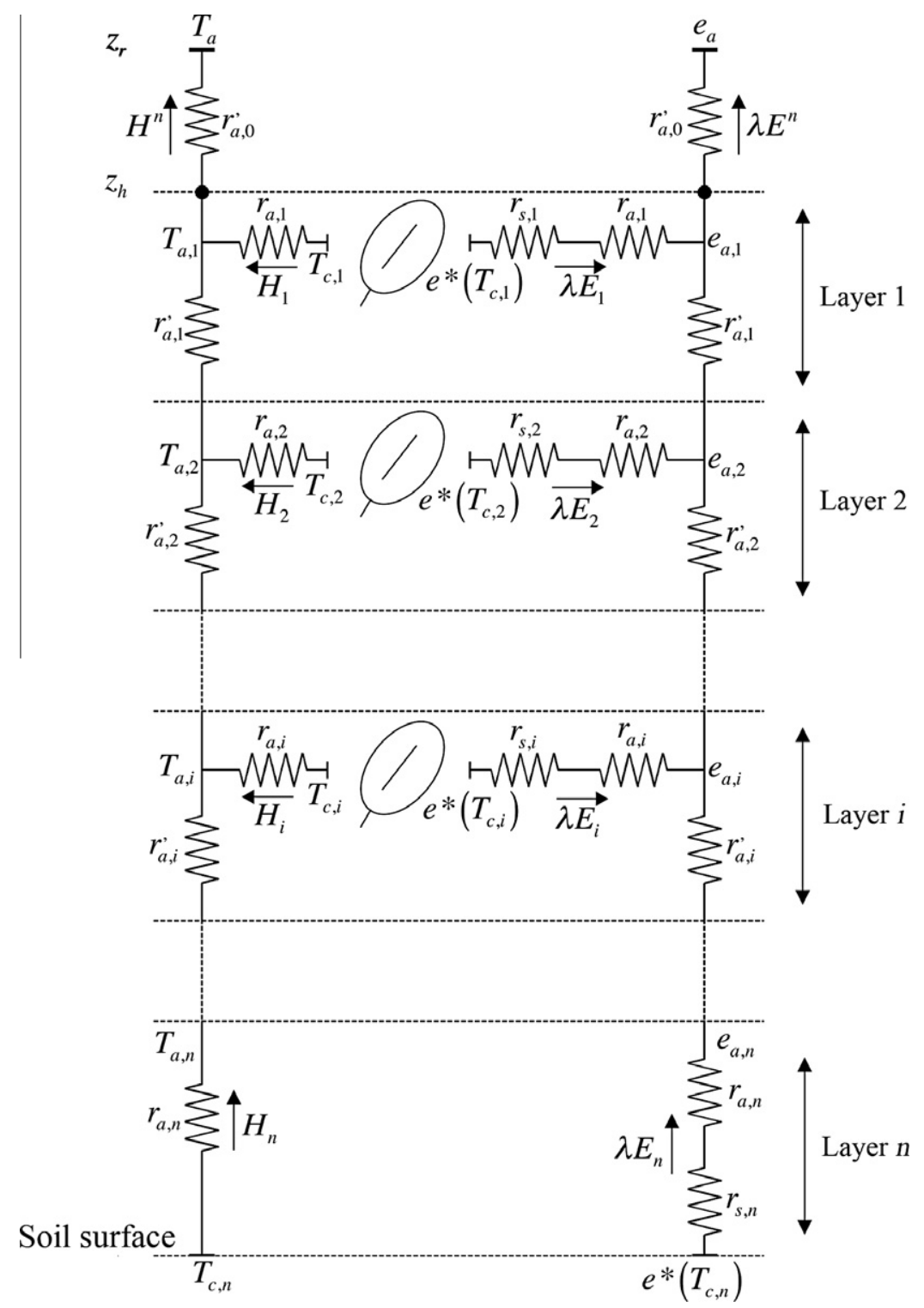

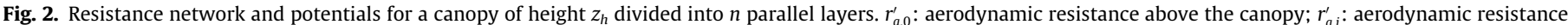
for the vertical transfer of heat and water vapour within layer $i$; $T_{a, i}$ : air temperature within layer $i$; $e_{a, i}$ : air water vapour pressure within layer $i$.

Eqs. (12) and (13) represent a simple formulation of the evaporation rate from a multi-component canopy. It generalizes for $n$ components the equations demonstrated by Lhomme et al. (2012) for $n=2$ and 3 . The first term involves the atmospheric demand $\left(\lambda E_{p}\right)$, multiplied by a combination of resistances, and the second term is a summation of the available energy $\left(A_{i}\right)$ of each component, each one multiplied by a combination of resistances. The contribution of each component is obtained from Eq. (11), once $\lambda E^{n}$ is calculated.

As already stated, Wallace (1997) proposed a similar (although more complex) formula for a canopy with amphistomatous components, without specifying however the steps of the mathematical demonstration (the resistance combination terms $C_{i}$ were not formally derived). Therefore, we establish in Appendix A that our formulation applied to amphistomatous components is equivalent to the one proposed by Wallace (1997). In this way, a clear validation of his formulation (our Eq. (30)) is provided.

\section{Examining and illustrating particular cases}

In this section we show how the general formulation demonstrated above (Eqs. (12) and (13)) restitutes the equations already established for canopies with one, two and three components. The particular case of $n$ identical components is also examined for its physical significance.

\subsection{One component $(n=1)$}

When only a single component is considered, Eq. (12) transforms into:

$\lambda E^{1}=R_{0} P_{1} \lambda E_{p}+\left(\frac{\Delta}{\gamma}\right) P_{1} A_{1} r_{a, 1} \quad$ with $\quad P_{1}=1 /\left(R_{0}+R_{1}\right)$.

Replacing $R_{0}$ and $R_{1}$ by their respective expressions (Eqs. (7) and (8)) and after some rearrangements the following expression is obtained:

$\lambda E^{1}=\frac{\Delta A+\rho c_{p} D_{a} /\left(r_{a, 0}+r_{a, 1}\right)}{\Delta+\gamma\left(\frac{r_{a, 0}+r_{1} r_{a, 1}+r_{s, 1}}{r_{a, 0}+r_{a, 1}}\right)}$.

If we consider an amphistomatous canopy ( $\left.v_{1}=1\right)$, Eq. (15) simplifies into: 
$\lambda E^{1}=\frac{\Delta A+\rho c_{p} D_{a} /\left(r_{a, 0}+r_{a, 1}\right)}{\Delta+\gamma\left(1+\frac{r_{s, 1}}{r_{a, 0}+r_{a, 1}}\right)}$.

Eq. (16) corresponds to a Penman-Monteith equation, where the leaf boundary-layer resistance $r_{a, 1}$ of the component is added to the aerodynamic resistance $r_{a, 0}$ between the canopy source height and the reference height. The inclusion of this additional air resistance is explained by the fact that the effective source of heat and water vapour is not taken here at the mean canopy source height $\left(z_{m}=d+z_{0}\right)$, as is the case for the common formulation of the "big leaf" model, but at the level of the foliage itself with temperature $T_{c, 1}$. The additional resistance $r_{a, 1}$ can be considered as equivalent to the extra resistance $r_{e x}=B^{-1} / u_{*}$ linked to the concept of $k B^{-1}$, discussed in many studies (e.g., Garratt and Hicks, 1973).

\subsection{Two components $(n=2)$}

When two components (substrate + vegetation) are considered, Eq. (12) is written as:

$\lambda E^{2}=R_{0}\left(P_{1}+P_{2}\right) \lambda E_{p}+\left(\frac{\Delta}{\gamma}\right)\left(P_{1} A_{1} r_{a, 1}+P_{2} A_{2} r_{a, 2}\right)$,

with

$P_{1}=\frac{R_{2}}{R_{0} R_{1}+R_{0} R_{2}+R_{1} R_{2}}$,

$P_{2}=\frac{R_{1}}{R_{0} R_{1}+R_{0} R_{2}+R_{1} R_{2}}$

These equations are similar to those proposed by Lhomme et al. (2012, Eqs. (16)-(22)) as an alternative form of the ShuttleworthWallace formulation for sparse crops.

\subsection{More than two components $(n>2)$}

The case $n=3$ leads to results analogous to the two-component model: Eq. (12) transforms into the reformulated "clumped" model given by Lhomme et al. (2012, Eq. (33)). This formulation can be applied to many vegetation types already treated in the literature, with structure equivalent to that represented by our model (Fig. 1): for instance, the tropical savannah in Niger, consisting of bushes, grass and bare soil (Dolman, 1993) or a shrub-land in southeastern Spain (Brenner and Incoll, 1997; Domingo et al., 1999), where shrubs, soil under shrubs and bare soil outside shrubs constitute the three components of the model. A similar representation (vegetation plus two soil components) was employed by Zhang et al. (2008) for a vineyard in an arid region of northwest China. The formulation with $n=4$ can be applied to the Sahelian savannah described and modelled by Verhoef and Allen (2000), which is composed of bushes, herbs, grass and bare soil. Our generalized formulation is also suitable for modelling the mountain grasslands energy exchange (Wohlfahrt et al., 2001), where several components and species must be distinguished, each one characterised by different structural and functional properties. Another example could be the sparse mixed-species shrub canopy of Arizona studied and modelled by Stannard and Weltz (2006).

Wallace and Verhoef (2000) thoroughly discussed the practical interest of developing interactive multi-component models, such as the ERIN model, for mixed-plant communities in a large range of vegetation systems, both natural and man-made: crop association, crop/weed mixture, agroforestry. They pointed out, nevertheless, the difficulties to correctly define the in-canopy aerodynamic resistances.

\subsection{Identical components}

It is interesting to consider the particular case where all the $n$ components of the canopy are identical, i.e., with the same elementary characteristics (leaf area index, leaf stomatal resistance and leaf boundary-layer resistance) and where they all receive the same load of available energy $\left(A_{i}\right)$. Given that soil surface cannot be identical to a vegetation component, practically it means that the canopy has a leaf area index $\left(L A I=n L A I_{i}\right)$ large enough to completely cover the ground and that soil surface can be disregarded. Noting that $n A_{i}=A$ and $P_{i}=1 /\left(R_{i}+n R_{0}\right)$, Eq. (12) transforms into:

$\lambda E^{n}=\frac{n R_{0} \lambda E_{p}+(\Delta / \gamma) A r_{a, i}}{R_{i}+n R_{0}}$.

Developing $\lambda E_{p}$ (Eq. (10)), $R_{0}$ and $R_{i}$ (Eqs. (7) and (8)) leads to:

$\lambda E^{n}=\frac{\Delta A+\rho c_{p} D_{a} /\left(r_{a, 0}+r_{a, i} / n\right)}{\Delta+\gamma\left(\frac{r_{a, 0}+v_{i} r_{a, i} / n+r_{s, i} / n}{r_{a, 0}+r_{a, i} / n}\right)}$.

Eq. (21) with $v_{i}=1$ (amphistomatous case) is a Penman-Monteith equation, similar to Eq. (16). This is what could be expected from a canopy with $n$ identical components, since it constitutes a kind of "big-leaf" with homogeneous characteristics. Bearing in mind Eqs. (2) and (3), the bulk expressions for the stomatal and boundary-layer resistances in Eq. (21) can be expressed as a function of the leaf area index of the whole canopy: $r_{s, i} / n=v_{i} r_{s, l, i} /(2 L A I)$ and $r_{a, i} / n=v_{i} r_{a, l, i} /(2 L A I)$.

It is worthwhile noting that when $n \rightarrow \infty$ (i.e., $L A I \rightarrow \infty$ with constant component resistances $r_{s, l, i}$ and $r_{a, l, i}$ ), Eq. (21) transforms into the Penman equation $\lambda E_{p}$ (potential evaporation) given by Eq. (10), where only the aerodynamic resistance above the canopy $\left(r_{a, 0}\right)$ is present. This also means that $D_{m} \rightarrow 0$. Such a result, obviously obtained by implicitly assuming soil water to be not limiting, could be expected: as a matter of fact, the infinite number of components tends to cancel all the inner resistances to evaporation.

\section{Conclusion}

As stated in the introduction, a new formulation for the evaporation from a multi-component canopy representing a mixture of neighbouring species has been obtained. In theory, this formulation applies to canopies without significant vertical stratification. The total evaporation from the canopy is determined by Eq. (12) and the component evaporations by Eq. (11). These new equations are now fully justified and mathematically demonstrated. They are more concise than those proposed by Wallace (1997) and do not involve the confusing "Penman-Monteith" terms. They also allow for the stomatal characteristics of each component. The simple cases ( $n=1$ or 2 ) are easily inferred from the general formulation and its asymptotic limit for identical components $(n \rightarrow \infty)$ is in accordance with the basic knowledge on evaporation modelling.

The generalized approach of the evaporation from mixed-plant communities, as developed here, is worth for the theoretical and conceptual framework it defines, but also for its concrete applications when applied to two, three or more components. Nevertheless, when applying these formulations to the real world, some practical problems remain difficult to tackle, such as defining reliable expressions for inner canopy resistances.

\section{Appendix A. Derivation of the ERIN formulation}

Starting from the general formulation of Eq. (12), it is possible to retrieve the formulae originally proposed by Wallace (1997) 
for the evaporation from multi-component canopies. First, (Eq. (12)) should be rewritten as:

$\lambda E^{n}=\sum_{i=1}^{n} P_{i}\left[R_{0}\left(\frac{\Delta A+\rho c_{p} D_{a} / r_{a, 0}}{\Delta+\gamma}\right)+\left(\frac{\Delta}{\gamma}\right) A_{i} r_{a, i}\right]$.

Replacing $R_{0}$ by its expression (Eq. (7)) and then multiplying and dividing by $r_{a, 0}+r_{a, i}$ yields:

$\lambda E^{n}=\sum_{i=1}^{n}\left[P_{i}\left(r_{a, 0}+r_{a, i}\right) / \gamma\right]\left[\Delta \frac{\left(A r_{a, 0}+A_{i} r_{a, i}\right)}{r_{a, 0}+r_{a, i}}+\frac{\rho c_{p} D_{a}}{r_{a, 0}+r_{a, i}}\right]$.

Noticing that:

$\frac{A r_{a, 0}+A_{i} r_{a, i}}{r_{a, 0}+r_{a, i}}=A-\frac{r_{a, i}\left(A-A_{i}\right)}{r_{a, 0}+r_{a, i}}$

leads to:

$\lambda E^{n}=\sum_{i=1}^{n}\left[P_{i}\left(r_{a, 0}+r_{a, i}\right) / \gamma\right]\left[\Delta A+\frac{\left[\rho c_{p} D_{a}-\Delta r_{a, i}\left(A-A_{i}\right)\right]}{r_{a, 0}+r_{a, i}}\right]$.

Eq. (25) can be rewritten in the form used by Wallace (1997)

$\lambda E^{n}=\sum_{i=1}^{n} C_{i} P M_{i}$,

where the "Penman-Monteith" terms and their coefficients are given by:

$P M_{i}=\frac{\Delta A+\frac{\left[\rho c_{p} D_{a}-\Delta r_{a, i}\left(A-A_{i}\right)\right]}{r_{a, 0}+r_{a, i}}}{\Delta+\gamma\left[1+\frac{r_{s, i}}{r_{a, 0}+r_{a, i}}\right]}$,

$C_{i}=P_{i}\left[R_{0}+r_{s, i}+\left(1+\frac{\Delta}{\gamma}\right) r_{a, i}\right]$.

Wallace (1997) defined slightly differently the $R$ coefficients specified by Eqs. (7) and (8): $R_{0}^{\prime}=\gamma R_{0}$ and $R_{i}^{\prime}=\gamma R_{i}$. He also implicitly considered amphistomatous components $\left(v_{i}=1\right)$. Therefore, the coefficients $C_{i}$ can be rewritten (with Wallace's notations) as:

$C_{i}=\frac{R_{0}^{\prime}+R_{i}^{\prime}}{\left.R_{i}^{\prime} 1+R_{0}^{\prime} \sum_{j=1}^{n} 1 / R_{j}^{\prime}\right)}$.

Dividing each term by $R_{0}^{\prime}+R_{i}^{\prime}$ and rearranging gives:

$C_{i}=\left(1+\frac{\sum_{j=1, j \neq i}^{n} 1 / R_{j}^{\prime}}{1 / R_{0}^{\prime}+1 / R_{i}^{\prime}}\right)^{-1}$.
This formulation, now fully demonstrated, is exactly the one given by Wallace (1997, Eq. (36)) and also mentioned by Wallace and Verhoef (2000, Eq. (18)).

\section{References}

Brenner, A.J., Incoll, L.D., 1997. The effect of clumping and stomatal response on evaporation from sparsely vegetated shrub-lands. Agric. For. Meteorol. 84, 187 205.

Choudhury, B.J., Monteith, J.L., 1988. A four-layer model for the heat budget of homogeneous land surfaces. Q. J. Roy. Meteorol. Soc. 114, 373-398.

Dolman, A.J., 1993. A multiple-source land surface energy balance model for use in general circulation models. Agric. For. Meteorol. 65, 21-45.

Domingo, F., Villagracia, L., Brenner, A.J., Puigdefabregas, J., 1999 Evapotranspiration model for semi-arid shrub-lands tested against data from SE Spain. Agric. For. Meteorol. 95, 67-84.

Garratt, J.R., Hicks, B.B., 1973. Momentum, heat and water vapour transfer to and from natural and artificial surfaces. Q. J. Roy. Meteorol. Soc. 99, 680687.

Huntingford, C., Allen, S.J., Harding, R.J., 1995. An intercomparison of single and dual-source vegetation-atmosphere transfer models applied to transpiration from Sahelian savannah. Bound. - Lay. Meteorol. 74, 397-418.

Jones, H.G., 1992. Plants and Microclimate. second ed. Cambridge University Press. Lhomme, J.P., 1988. Extension of Penman's formulae to multi-layer models. Bound. - Lay. Meteorol. 42, 281-291.

Lhomme, J.P., Chehbouni, A., 1999. Comments on dual-source vegetationatmosphere transfer models. Agric. For. Meteorol. 94, 269-273.

Lhomme, J.P., Montes, C., Jacob, F., Prévot, L., 2012. Evaporation from heterogeneous and sparse canopies: on the formulations related to multi-source representations. Bound. - Lay. Meteorol. 144, 243-262.

Monteith, J.L., 1965. Evaporation and the environment. Sympos. Soc. Exp. Biol. 19 205-234.

Shuttleworth, W.J., Gurney, R.J., 1990. The theoretical relationship between foliage temperature and canopy resistance in sparse crops. Q. J. Roy. Meteorol. Soc. 116, 497-519.

Shuttleworth, W.J., Wallace, J.S., 1985. Evaporation from sparse crops - an energy combination theory. Q. J. Roy. Meteorol. Soc. 111, 839-855.

Stannard, D.I., Weltz, M.A., 2006. Partitioning evapotranspiration in sparsely vegetated rangeland using a portable chamber. Water Resour. Res. 42, W02413.

Verhoef, A., Allen, S.J., 2000. A SVAT scheme describing energy and $\mathrm{CO}_{2}$ fluxes for multi-component vegetation: calibration and test for a Sahelian savannah. Ecol. Model. 127, 245-267.

Waggoner, P.E., Reifsnyder, W.E., 1968. Simulation of the temperature, humidity and evaporation profiles in a leaf canopy. J. Appl. Meteorol. 7, 400-409.

Wallace, J.S., 1997. Evaporation and radiation interception by neighbouring plants. Q. J. Roy. Meteorol. Soc. 123, 1885-1905.

Wallace, J.S., Verhoef, A., 2000. Interactions in mixed-plant communities: light water and carbon dioxide. In: Marshall, Roberts (Eds.). Leaf Development and Canopy Growth. Sheffield Biological Science Series, Sheffield Academic Press, pp. 204-250.

Wohlfahrt, G., Bahn, M., Tappeiner, U., Cernusca, A., 2001. A multi-component, multi-species model of vegetation-atmosphere $\mathrm{CO}_{2}$ and energy exchange for mountain grasslands. Agric. For. Meteorol. 106, 261-287.

Zhang, B., Kang, S., Li, F., Zhang, L., 2008. Comparison of three evapotranspiration models to Bowen ratio-energy balance method for a vineyard in an arid desert region of northwest China. Agric. For. Meteorol. 148, 1629-1640. 